\title{
Modeling Annual Poverty In A Metropolitan Area
}

Robert G. Mogull, (Email: mogullr@ csus.edu), California State University, Sacramento

\begin{abstract}
This study establishes a methodology to create annual rates of poverty within a metropolitan region. The site selected is Los Angeles/Long Beach, where trend lines are separately calculated for all residents, whites, blacks, Hispanics, female family heads, the elderly and children. The most striking evidence is the surge in poverty among Hispanics and children, which pulls up the overall rate for the region. The trends foretell the formation of an immense impoverished Hispanic underclass.
\end{abstract}

\section{Introduction and Goals}

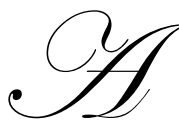

rticle I, Section II of the U.S. Constitution specifies that an enumeration of the population shall be made every 10 years. Consequently, the Bureau of the Census conducts decennial counts of the population and, at the same time, it compiles data on income for families and individuals (for the year immediately preceding each census year). Since 1960, the Bureau has also estimated poverty at 10-year intervals for the nation, regions, states, counties, urban and rural areas, and tracts. The census surveys of poverty have been obtained from samples ranging between $15 \%$ and $25 \%$ of housing units. In addition and also since 1960, the Bureau has obtained annual data on income and poverty (for 1959 on) and has published it in March issues of the Current Population Reports. The Current Population Surveys are based upon national samples over the years, which have ranged between 33,500 and 65,500 noninstitutional civilian households. This annual data has been collected, however, only for the nation and for states. Except for the decennial censuses, no data on poverty are regularly compiled for substate levels.

Hence, one objective of this study is to create a methodology which can be used to estimate annual rates of poverty for substate jurisdictions. The goal is to establish a straightforward procedure which may be easily applied in a variety of geographic settings. A second objective is to estimate annual rates of poverty for a demonstration metropolitan area. This purpose is intended to fill in for the absence of official rates. The third objective is to extend the methodology to allow for a projection of rates of poverty. The projected incidence of poverty will be based upon the historical pattern.

The basic justification for this project can be traced to a comment by Wendell Primus, who stated that "The real importance of a . . poverty measure is not the (true) number who are poor in any one year but the indicator's ability to show whether the number is decreasing or increasing over time" (1995, p. 27). Hence, the underlying goal is to create a valid and reliable charting of long-term poverty trends. The assumption made by the planned methodology is that smoothed linkages between discrete benchmarks (which have been established by the decennial censuses) will yield a valid and reliable charting of long-term trends. The trends themselves are the product of a complex combination of economic, social and psychological factors which can affect the incidence of poverty.

Readers with comments or questions are encouraged to contact the authors via email.

\section{Methodology}

The methodology to be used is patterned after a technique that had been employed successfully by Robert 
G. Mogull (1991, 1993, Spring 1998, 1998) in estimating time-series poverty for the state of California. The technique relied on valid benchmarks for discrete time periods, where the benchmarks were the official poverty rates compiled by the Bureau of the Census in decennial censuses. A trend line was fitted to the discrete benchmark data points. From the basic underlying trend line, interim annual poverty rates were then determined. The trend line was extrapolated in order to provide forecasts.

At the time of this writing, the U.S. Census Bureau has published poverty benchmarks for the years 1959, 1969, 1979 and 1989 (1972, April 1973, May 1973, June 1973, 1975, 1985, 1993). (These are the dates of income received rather than the census dates of data collection.) These four dates will provide the anchors for the resulting trend lines. Annual poverty rates will be read from the lines -- that is, will be determined from the specific regression equations for the lines. The trend in years will serve as a general and overall net proxy for a variety of economic, social and psychological factors, which can affect poverty rates over time.

Both simple monomial linear and simple polynomial curvilinear regression models will be used to create the trend lines. These models will be able to account for changes over time in the direction of the trends. The dependent variable is the percentage rate of poverty, while the explanatory variable is the year of pre-tax earned money income. The predictor variable (i.e., year) will be expressed simultaneously to various degrees. Since the goal is to account for the maximum amount (i.e., proportion) of the variation of the dependent variable over time, the best-fit model will be identified by the largest coefficient of determination $\left(r^{2}\right)$.

As many terms will be retained in the model as possible, regardless of whether the individual terms are statistically significant. Although collinearity or multicollinearity will certainly be present, for the purpose of this study and with our goal clearly in mind, intercorrelations among the predictor terms will be ignored. Nevertheless, the p-value of each term will be cited in order to indicate the reliability of linearity and curvature.

Two error statistics will be reported (the mean absolute error and the standard error of estimate) in order to reveal the tightness of the overall data fit around the line (curve). An F test statistic (with its accompanying p-value) will indicate the comparative relationship in the model between the "explained" and the "unexplained" variances.

The above methodology will be employed for each of seven different (but not mutually exclusive) population segments. The population groups are: all residents, whites, blacks, Hispanics, female family heads, the elderly (age 65 and over), and children (related by blood or adoption to the householder and below the age of 18). The demonstration site for this study is the Los Angeles-Long Beach (LA/LB) Standard Metropolitan Statistical Area (since 1959) and Primary Metropolitan Statistical Area (since 1983). This metropolis is the second largest in the nation, with a Consolidated Metropolitan Statistical Area population in 1996 of about 151/2 million.

The official decennial poverty rates for each group, as collected and reported by the U.S. Bureau of the Census, are presented below in Table 1. These rates will be the benchmarks or anchors for the smoothed trend lines.

\section{Official Definition of Poverty}

Measures of poverty that are used by the Census Bureau were originally developed in 1964 by Mollie Orshansky $(1965,1969)$ of the Social Security Administration and subsequently revised by federal interagency committees in 1969 and 1981. Income levels for delineating the poor are based upon the minimal cost of a low-income nutritionally adequate food plan, which was designed in 1961 by the U.S. Department of Agriculture. A 1955 Household Food Consumption Survey by the Agriculture Department determined that an average low-income family spent about one-third of its after-tax income on food. Consequently, in order to determine poverty income thresholds, Orshansky multiplied by three the cost of an Economy Food Plan. The income thresholds were set to cover minimal needs for food, clothing, shelter and a little extra for other essentials. In 1969, the Bureau of the Budget (now the Office of Management and Budget) prescribed the thresholds as the official standard to be used by all federal agencies.

Table 1.

Census Poverty Rates for Los Angeles/Long Beach 


\begin{tabular}{lrrrr}
\multicolumn{4}{c}{ Percentage } \\
\cline { 2 - 5 } Group & \multicolumn{4}{c}{ Year } \\
\cline { 2 - 5 } All Residents & 1959 & 1969 & 1979 & 1989 \\
Whites & 13.0 & 10.9 & 13.4 & 15.1 \\
Blacks & 11.4 & 9.2 & 9.9 & 10.6 \\
Hispanics & 28.3 & 23.9 & 23.1 & 21.2 \\
Female Family Heads & na & 15.8 & 20.5 & 22.9 \\
Elderly & 32.1 & 28.1 & 30.3 & 26.5 \\
Children & na & 14.8 & 9.2 & 9.2 \\
\hline
\end{tabular}

na = statistic not available.

Source: Bureau of the Census, U.S. Department of Commerce.

The poverty indexes, which are used by the Census Bureau, are determined by pre-tax money income only. They reflect the different income requirements of families and of unrelated individuals. Currently, income cut-off levels vary according to the number of family members and the age of the family head. Prior to 1982, however, the cut-off levels also considered whether a family lived on a farm and the gender of the head of household. Since 1965, the poverty indexes have been adjusted annually for changes in the national Consumer Price Index (now, for All Urban Consumers). However, no adjustments are made for regional differences in living expenses. Despite numerous criticisms, "for the foreseeable future" the Census Bureau will continue to use the present definition of poverty and its methods of tabulation (Focus, 1998, pp. 2-3).

\section{Errors in Estimates}

There are three categories of error that occur in the Census Bureau's estimates of poverty. One category is sampling variability. This refers to the variability in evidence from one sample to another from the same population. Such variation is attributable to chance alone.

A second category of error is nonsampling variability and it is caused by a large variety of factors. Potential causes may include a lack of information (e.g., from nonresponses to questionnaires), misinterpretation of the survey's questions, improper imputations of missing questionnaire data, and human errors in the recording, coding and processing of the data. Nonsampling variation can also occur from an undercoverage of a segment of the population. Such undercoverage can systematically vary by age, gender, and racial or ethnic group. Nonsampling errors may produce biased evidence.

An additional and separate source of error occurs as a consequence of the changing definitions of particular racial and ethnic groups which have been used by the Census Bureau. For example; in the 1960 census, blacks were classified under the more general category of "nonwhites." This category included such diverse population segments as blacks, American Indians, Japanese, Chinese, Filipinos, Koreans, Hawaiians, Asian Indians, Malayans, Eskimos, Aleuts, and others. Beginning with the 1970 census, however, blacks were classified separately.

A similar problem arises with the Hispanic category. Poverty data for this group did not exist prior to the 1970 census. Before then, Hispanics were usually included within the "white" classification. Over the years, Hispanics have been alternatively defined by the Census Bureau as persons of Spanish language, surname, origin or descent. The category has included immigrants and descendents from Mexico, Puerto Rico, Cuba, Spain, the West Indies, Central and South America, Indians and those of mixed ancestry. Furthermore, persons of Hispanic origin have been of any race. Such inconsistencies produced unknown degrees of bias from one census to the next and, thus, can distort the benchmark estimates.

\section{First-Stage Evidence}

The first stage in the analysis of the data is an identification of the best-fit model for each separate population segment. Two regression models were tried -- a simple monomial linear and a simple polynomial curvilinear. Table 2 presents the resulting evidence for each group and each model. Statistics are presented for sample size (n), 
mean absolute error (MAE), standard error of estimate (s.e.), coefficient of determination $\left(r^{2}\right)$, coefficient of determination adjusted for degrees of freedom $\left(\mathrm{r}^{2}\right)$, the test statistic for the full model $(\mathrm{F})$ and its significance level $(\mathrm{p})$.

Table 2.

Data Fits of the Models

\begin{tabular}{|c|c|c|c|c|c|c|c|}
\hline All & $\frac{n}{4}$ & MAE & s.e. & $\underline{\underline{r}^{2}}$ & $\underline{\underline{\underline{r}^{2}}}$ & $\underline{F}$ & $\mathrm{p}$ \\
\hline$P=f(Y)$ & & .95 & 1.59 & .43 & .15 & 1.53 & .34 \\
\hline$* \mathrm{P}=\mathrm{f}\left(\mathrm{Y}, \mathrm{Y}^{2}\right)$ & & .54 & 1.21 & .84 & .51 & 2.57 & .40 \\
\hline Whites & 4 & & & & & & \\
\hline $\mathrm{P}=\mathrm{f}(\mathrm{Y})$ & & .73 & 1.12 & .05 & .00 & .11 & .77 \\
\hline$* \mathrm{P}=\mathrm{f}\left(\mathrm{Y}, \mathrm{Y}^{2}\right)$ & & .29 & .65 & .84 & .53 & 2.67 & .39 \\
\hline Blacks & 4 & & & & & & \\
\hline$P=f(Y)$ & & .67 & 1.15 & .90 & .85 & 18.31 & .05 \\
\hline$* \mathrm{P}=\mathrm{f}\left(\mathrm{Y}, \mathrm{Y}^{2}\right)$ & & .47 & 1.05 & .96 & .88 & 11.76 & .20 \\
\hline Hispanics & 3 & & & & & & \\
\hline $\mathrm{P}=\mathrm{f}(\mathrm{Y})$ & & .51 & .94 & .97 & .93 & 28.59 & .12 \\
\hline$* \mathrm{P}=\mathrm{f}\left(\mathrm{Y}, \mathrm{Y}^{2}\right)$ & & .00 & .00 & 1.00 & 1.00 & $\infty$ & .00 \\
\hline Female Heads & 4 & & & & & & \\
\hline$* \mathrm{P}=\mathrm{f}(\mathrm{Y})$ & & 1.22 & 1.93 & .59 & .38 & 2.86 & .23 \\
\hline$P=f\left(Y, Y^{2}\right)$ & & 1.22 & 2.73 & .59 & .00 & .72 & .64 \\
\hline Elderly & 3 & & & & & & \\
\hline$P=f(Y)$ & & 1.24 & 2.29 & .75 & .50 & 3.00 & .33 \\
\hline$* \mathrm{P}=\mathrm{f}\left(\mathrm{Y}, \mathrm{Y}^{2}\right)$ & & .00 & .00 & 1.00 & 1.00 & $\infty$ & .00 \\
\hline Children & 3 & & & & & & \\
\hline$P=f(Y)$ & & .78 & 1.43 & .94 & .89 & 16.87 & .15 \\
\hline$* \mathrm{P}=\mathrm{f}\left(\mathrm{Y}, \mathrm{Y}^{2}\right)$ & & .00 & .00 & 1.00 & 1.00 & $\infty$ & .00 \\
\hline
\end{tabular}

*Indicates the superior model.

In general, when there is a better data fit (between the two models), the MAE and s.e. are smaller, $\mathrm{r}^{2}$ and $\overline{\mathrm{r}}^{2}$ are larger, $\mathrm{F}$ is larger and $\mathrm{p}$ is smaller. Yet, some inconsistencies appear. A model which exhibits smaller errors (MAE and s.e.), for example, does not always produce a larger test statistic (F) or smaller significance level (p). Such inconsistencies are due to adjustments from the degrees of freedom. Consequently, since no single statistic can be relied upon to invariably identify the better-fit model, we must exercise judgment. It is, therefore, necessary to keep our goal firmly in mind. The objective is to identify the model for each separate group which best accounts for the variation in official poverty rates over time. Given this goal, the greatest weights should be assigned to statistics $r^{2}$ and MAE. Thus, the polynomial curvilinear models usually produce superior results.

There is, however, one exception -- female family heads (ffh). Regardless of which model is used, the MAE's and $\mathrm{r}^{2} \mathrm{~s}$ are the same. But, for all other statistics, the results obtained from the polynomial model are inferior. (That is, the s.e. and $\mathrm{p}$ are larger, while $\mathrm{r}^{2}$ and $\mathrm{F}$ are smaller.) The explanation for this inconsistency is due to the adjustments from degrees of freedom and can be seen by examining the data benchmarks. For all other groups, the trends in benchmarks do not exhibit more than one substantial change in direction (see Figure 1). However, the trend in benchmarks for ffh exhibits two substantial directional changes. With four data points, ideally it would be desirable to employ a model of the functional form $\mathrm{P}=\mathrm{f}\left(\mathrm{Y}, \mathrm{Y}^{2}, \mathrm{Y}^{3}\right)$. However, due to severe multicollinearity among the terms of such a model, a cubic polynomial expression cannot be forced. We are, therefore, limited to a model of the form $\mathrm{P}=\mathrm{f}\left(\mathrm{Y}, \mathrm{Y}^{2}\right)$-- although it is clearly inadequate. And, since the linear model yields equivalent statistics for MAE and $\mathrm{r}^{2}$, while displaying superior statistics for s.e., $\mathrm{r}^{2}, \mathrm{~F}$ and $\mathrm{p}$, the simple linear monomial expression is chosen for that group. 
Figure 1.

Los Angeles/Long Beach Census Poverty Rates: 1959-1989

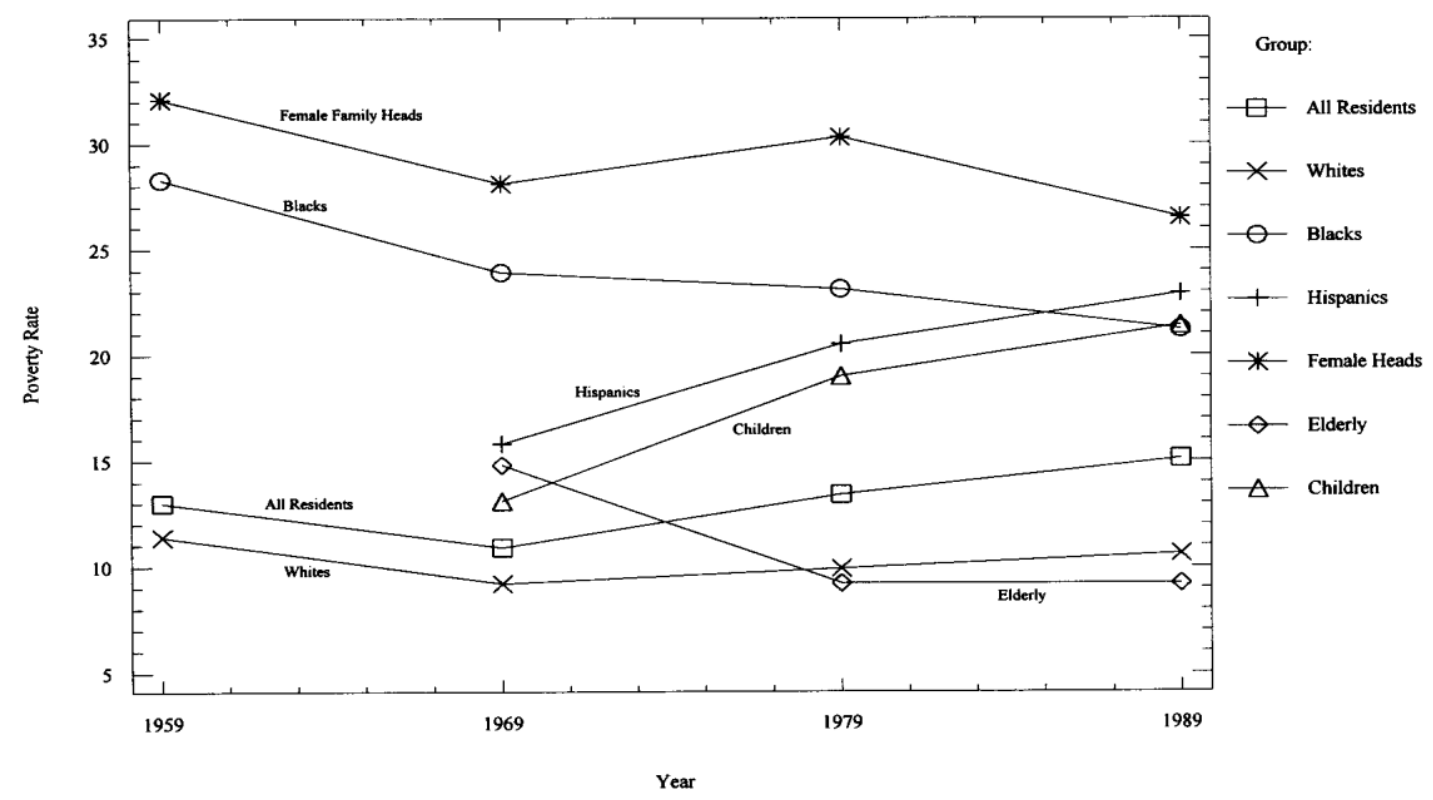

\section{Second-Stage Evidence}

In the first stage, a variety of criteria were examined in order to select the better-fit model for each of the seven population groups. The better specific regression equation for each group is listed in Table 3 , along with the p-value of each slope coefficient.

The seven best models can now be employed to provide the estimates and projections of smoothed annual rates of poverty for the complete time frame 1959 through 2000. The results are listed in the Appendix and are also illustrated in Figure 2.

Table 3.

Specific Regressions for Best-Fit Models*

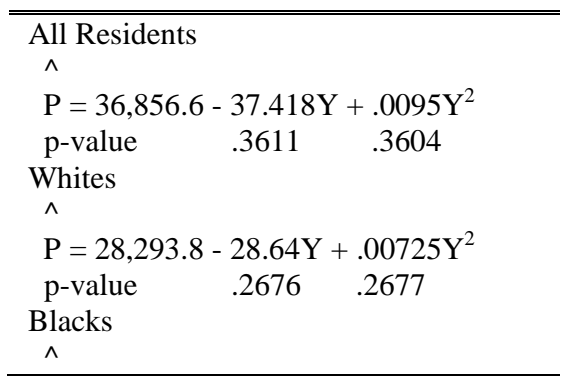




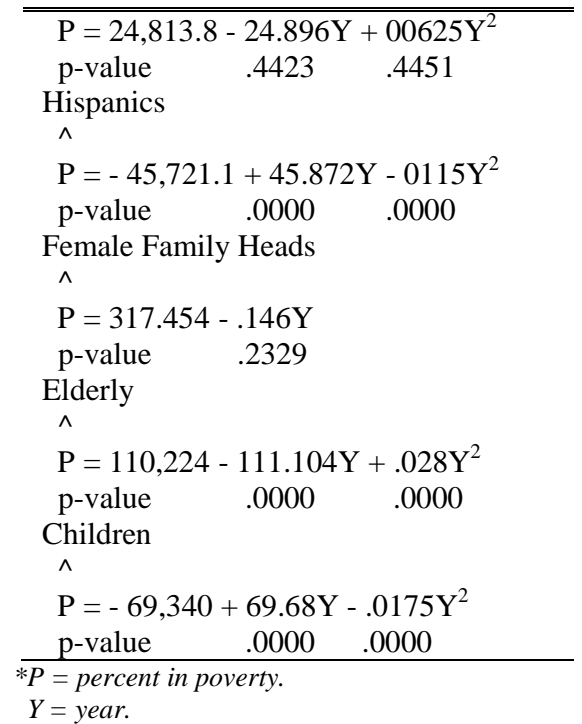

\section{Discussion of the Trend Evidence}

The most striking evidence is the rising rates of poverty over the years among both Hispanics and children. The long-term trend lines of these two groups have risen substantially (see Figure 2 and the Appendix). As illustrated in Figure 2, the paths of their trend lines are almost parallel, with the coefficient of correlation between their long-run poverty rates a positive .9953 . Hence, there is evidence of a direct and strong relationship between their temporal rates. This close correlation is most likely a consequence of the large number of children that typify Hispanic families. When Hispanics experience high rates of poverty, their children do also. But, in addition, the large size of the Hispanic families feeds back to further strain their already limited resources and causes even more prevalent poverty. It is a two-way street of "cause and effect."

Also revealed in Figure 2 is a steeply rising poverty rate for the overall population (i.e., for all residents) within the LA/LB metropolitan region. The rise has occurred despite sharp declines in rates for female family heads and blacks and a very modest rise for whites. It can therefore be attributed primarily to the exploding size of the Hispanic population. Between 1970 and 1990, whereas the overall population in LA County rose by 26\%, the Hispanic segment leaped by $213 \%$. In other words, the Hispanic share of the overall population jumped from $15 \%$ to $38 \%$ in just 20 years. And, according to estimates by the California Department of Finance (Heim, 1999), this demographic transition is likely to continue. The Hispanic share of the overall LA population is projected by the Finance Department to rise from $46 \%$ in year 2000 to $64 \%$ in year 2040. The convergence of these trends is exceptionally clear in foretelling an impending economic and social disaster. The evidence clearly foretells a very rapid formation of an immense impoverished underclass, which will be concentrated among the Hispanic residents. 
Figure 2.

Los Angeles/Long Beach Annualized Poverty Trends: 1959-2000

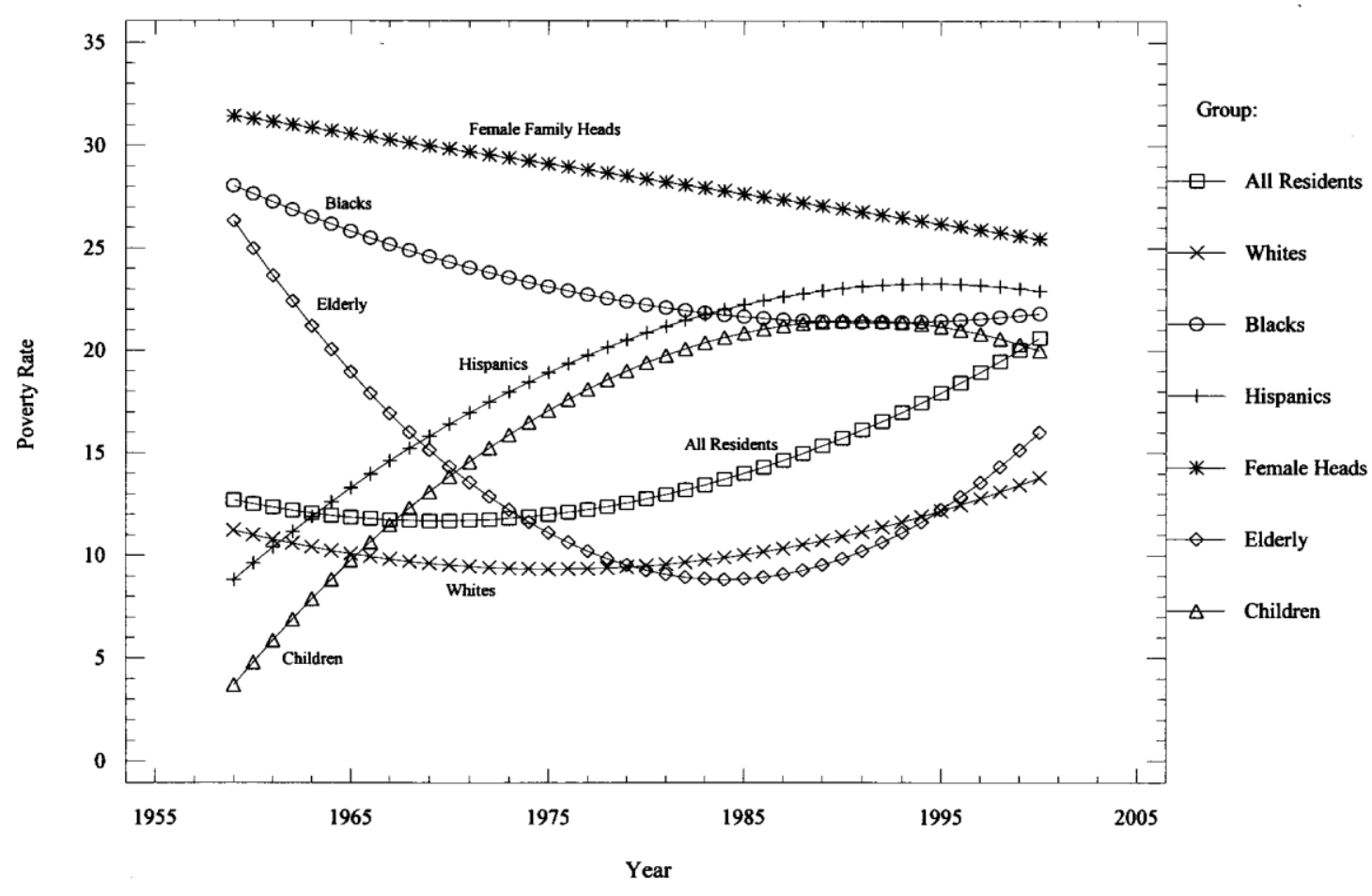

Yet, although poverty rates among Hispanics and children have exhibited significant growth, the rates of increase are diminishing and appear to have reached plateaus. The rate of poverty for Hispanics appears to have peaked in 1994. Consequently, concern over an unfolding disaster comes from the rapid growth of the Hispanic population (which carries the high poverty rate), rather than from a continuously increasing incidence of poverty within the Hispanic community.

Almost as striking as the trend phenomena for Hispanics and children are the trend rates for female family heads and for blacks. Whereas the rates for Hispanics and children rose dramatically, the rates for ffh's and blacks have declined substantially. This downward path is projected to continue for both groups, but is expected to taper off for blacks by year 2000 .

The trend in rates for the elderly has also declined markedly and significantly, but it too has leveled off and is projected to rise again. Over the 30 years of official estimates, the rates for whites first declined and then exhibited a slight upward turn. The projected upward curvature through year 2000 is modest and not statistically significant, but it does appear.

The poverty rate of all residents is derived from a combination of all population segments. While accounting for early rapid rises and later abatements in the rates of increase for Hispanics and children, the sharp drop-off then leveling and projected rise in rates for the elderly, the decline and then modest increase for whites, and the steep falls in rates for female family heads and blacks, the overall rate of poverty in LA/LB is increasing sharply. As already discussed, this is a consequence of (a) the previous sharp rise in poverty rates among Hispanics and children and (b) the continuing growth of the Hispanic share of the overall population.

An additional matter should be brought up. The poverty income threshold levels for individuals and families 
that are established by the Census Bureau are national and are not adjusted for regional differences in costs of living. But, living costs vary greatly among regions, states and cities. The cost of living in the LA/LB metropolitan area, for example, is more than $28 \%$ higher than the national average (U.S. Bureau of the Census, 1999, p. 498). Therefore, estimates of poverty in LA/LB both by the Census Bureau and in this study are significantly understated. The actual incidence of poverty in LA/LB is substantially worse than indicated. Consequently, the trend lines in Figure 2 should all be shifted up. It is unknown, however, how the adjustments in living costs would affect each separate group. Adjusting the poverty rates in LA/LB for above average costs of living is likely to affect each population segment to a different degree. Furthermore, if costs of living have risen more rapidly in LA/LB than nationally, then the slopes of the rising trend lines should become more steep, while the slopes of the declining trend lines should become less steep.

\section{Some Possible Explanations}

The purpose of this study was to develop and demonstrate a tool to estimate and project annual rates of poverty among various demographic groups within a metropolis. It was not the purpose of this paper to attempt to explain why a specific group experienced either an increase or decrease in its incidence of poverty. Nevertheless, in this section, several possible explanations are offered for each separate population segment. They should, however, be viewed as an agenda to be carefully explored in future research. At this point, they represent speculations and hypotheses.

The decline in poverty rates among female family heads may be due to several factors -- such as the general growth in the local economy (which offers both more employment opportunities and rising pay levels), increasing rates of female labor force participation, a reduction in gender-traditional jobs (with its consequent expansion of opportunities), less job discrimination (especially at supervisory and managerial levels), the growth of service oriented jobs (where women traditionally find greater opportunities), and the proliferation of day care facilities.

The decline in poverty rates among blacks may also be due to the general growth of the local economy, less employment discrimination, less housing segregation (which allows blacks to reside closer to the available jobs), and improved self-images (which raises levels of aspiration and achievement).

The decline in poverty rates among the elderly may be closely tied to the growth of service sector jobs in particular (which provides more employment opportunities and also allows for prolonged labor force attachment) and to improved health (which also permits extended participation in the labor force).

The striking rise in poverty rates among Hispanics can probably to tied to several factors -- such as increases in both legal and illegal immigration, greater competition for low wage jobs (which is aggravated by increased immigration), comparatively low employment skills, an underinvestment in education, a language barrier, a static job market for the low skilled, and a tendency to have many children. These factors may all serve to depress, or at least constrain, Hispanic incomes.

The even stronger increase in poverty among children is, as discussed previously, probably a phenomenon tied closely to the rising incidence of poverty among Hispanics in general. This connection is most likely a consequence of the rising Hispanic poverty rates, but also of the penchant of Hispanic families to have many children.

The poverty rate for whites has been and is projected to remain fairly constant. Yet, the poverty rate for the aggregate of residents in LA/LB is rising. This overall increase is caused by the strong upward pull of poverty among Hispanics and children. As the Hispanic share of the total population increases, it generates an ever larger influence on the general population.

\section{Summary and Conclusions}

In this article, a methodology was established to create annual estimates and projections of poverty rates within a demonstration metropolitan area. The greater Los Angeles and Long Beach Consolidated Metropolitan Statistical Area was the site selected. Using decennial census data as discrete benchmarks, continuous smoothed linkages were created for each of seven nonmutually exclusive segments of the population. The methodology was patterned after a technique that had been used by the author in estimating annual poverty for the state of California. Simple linear and curvilinear regression models were run to identify the best data fits. 
The evidence from the resulting trend lines (curves) revealed declining poverty rates for female family heads and blacks, declining and then increasing rates for the elderly and roughly stable rates for whites. The most striking evidence is the sharply increasing rates for Hispanics and children, where the poverty within these two groups is closely related. Partly as a consequence of the sharp growth in the incidence of poverty among Hispanics and children, the rate of poverty is also rapidly rising for the overall population in the metropolitan region.

The projected growth in poverty for the general population is primarily caused by the explosion in the size of the Hispanic segment, rather than from an increase in the incidence of poverty within the group. The evidence very clearly predicts the formation of an immense impoverished Hispanic underclass within the greater LA/LB metropolitan region.

\section{Suggestions for Future Research}

This study lends itself to a variety of divergent paths for further research. For example: (1) a follow-up study could employ new evidence compiled by the year 2000 Census. This would provide additional and more current benchmarks of LA/LB poverty. (2) Year 2000 Census data could also be compared to the projections generated in this paper. This would serve to validate (or not) the methodology. (3) The methodology that was developed here could be applied to other jurisdictions throughout the nation. (4) In the section under "Some Possible Explanations," a large variety of hypothetical causes of the trends is offered. These could be carefully explored and tested. Thus, this paper offers an agenda of many opportunities for further research.

\section{References}

1. $\quad$ Focus (no author cited), Vol. 19, No. 2, pp. 2-3, 1998.

2. Heim, Mary, Assistant Chief, Demographic Research Unit, Department of Finance, State of California, Sacramento, California, 1999.

3. Mogull, Robert G., "Annual Estimates of California's Poor: 1959 Through 1990," American Journal of Economics and Sociology, Vol. 50, No. 3, pp. 299-312, 1991.

4. Mogull, Robert G., "Annual California Poverty Estimates: Updated and Revised for 1960-2000," American Journal of Economics and Sociology, Vol. 52, No. 2, pp. 241-245, 1993.

5. Mogull, Robert G., "The Incidence of Annual State Poverty: The Case of California," Southern Business Review, Vol. 24, No. 1, pp. 25-37, spring 1998.

6. Mogull, Robert G., "The Incidence of California Poverty by Population Segment," The Social Science Journal, Vol. 35, No. 4, pp. 627-634, 1998.

7. Orshansky, Mollie, "Counting the Poor: Another Look at the Poverty Profile," Social Security Bulletin, Vol. 28, No. 1, pp. 3-29, 1965.

8. $\quad$ Orshansky, Mollie, "How Poverty is Measured," Monthly Labor Review, Vol. 92, No. 2, pp. 37-41, 1969.

9. $\quad$ Primus, Wendell, "Comments," Focus, Vol. 17, No. 1, p. 27, 1995.

10. U.S. Bureau of the Census, Department of Commerce, 1970 Census of Population, General Social and Economic Characteristics, "California," PC(1)-C6, Washington, D.C., p. 6-574, April 1972.

11. U.S. Bureau of the Census, Department of Commerce, 1970 Census of Population, Characteristics of the Population, "Detailed Characteristics," PC(1)-D, Vol. I, Part 6, Section 2, Washington, D.C., p. 6-2537, April 1973.

12. U.S. Bureau of the Census, Department of Commerce, 1970 Census of Population, Subject Reports, "Negro Population," PC(2)-1B, Washington, D.C., p. 191, May 1973.

13. U.S. Bureau of the Census, Department of Commerce, 1970 Census of Population, Subject Reports, "Persons of Spanish Origin," PC(2)-1C, Washington, D.C., p. 182, June 1973.

14. U.S. Bureau of the Census, Department of Commerce, 1970 Census of Population, Supplementary Report, "Poverty Status in 1969 and 1959 of Persons and Families, for States, SMSA's, Central Cities, and Counties: 1970 and 1960," PC(S1)-105, Washington, D.C., pp. 11, 20, Dec. 1975.

15. U.S. Bureau of the Census, Department of Commerce, 1980 Census of Population, Subject Reports, "Poverty Areas in Large Cities," PC80-2-8D, Washington, D.C., p. 17, Feb. 1985.

16. U.S. Bureau of the Census, Department of Commerce, 1990 Census of Population, Social and Economic Characteristics, "Metropolitan Areas," CP-2-1B, Section 1, Washington, D.C., pp. 73, 368, 396, 483, Nov. 1993.

17. U.S. Bureau of the Census, Department of Commerce, Statistical Abstract of the United States: 1999, Washington, D.C., 1999. 
Appendix

Los Angeles/Long Beach Annual Poverty Rates by Group

\begin{tabular}{rrrrcccc}
\hline \hline Year & All & Whites & Blacks & Hispanics & Females & Elderly & Children \\
\hline 1959 & 12.7 & 11.2 & 28.0 & 8.8 & 31.4 & 26.3 & 3.7 \\
1960 & 12.5 & 11.0 & 27.6 & 9.6 & 31.3 & 25.0 & 4.8 \\
1961 & 12.4 & 10.8 & 27.3 & 10.4 & 31.1 & 23.6 & 5.9 \\
1962 & 12.2 & 10.6 & 26.9 & 11.2 & 31.0 & 22.4 & 6.9 \\
1963 & 12.1 & 10.4 & 26.5 & 11.9 & 30.9 & 21.2 & 7.9 \\
1964 & 12.0 & 10.2 & 26.2 & 12.6 & 30.7 & 20.0 & 8.8 \\
1965 & 11.9 & 10.1 & 25.8 & 13.3 & 30.6 & 18.9 & 9.8 \\
1966 & 11.8 & 9.9 & 25.5 & 14.0 & 30.4 & 17.9 & 10.7 \\
1967 & 11.7 & 9.8 & 25.2 & 14.6 & 30.3 & 16.9 & 11.5 \\
1968 & 11.7 & 9.7 & 24.9 & 15.2 & 30.1 & 16.0 & 12.3 \\
1969 & 11.7 & 9.6 & 24.6 & 15.8 & 30.0 & 15.1 & 13.1 \\
1970 & 11.7 & 9.5 & 24.3 & 16.4 & 29.8 & 14.3 & 13.9 \\
1971 & 11.7 & 9.5 & 24.0 & 16.9 & 29.7 & 13.6 & 14.6 \\
1972 & 11.8 & 9.4 & 23.8 & 17.5 & 29.5 & 12.9 & 15.2 \\
1973 & 11.8 & 9.4 & 23.5 & 18.0 & 29.4 & 12.2 & 15.9 \\
1974 & 11.9 & 9.3 & 23.3 & 18.5 & 29.3 & 11.6 & 16.5 \\
1975 & 12.0 & 9.3 & 23.1 & 18.9 & 29.1 & 11.1 & 17.1 \\
1976 & 12.1 & 9.3 & 22.9 & 19.3 & 29.0 & 10.6 & 17.6 \\
1977 & 12.2 & 9.4 & 22.7 & 19.8 & 28.8 & 10.2 & 18.1 \\
1978 & 12.4 & 9.4 & 22.5 & 20.2 & 28.7 & 9.8 & 18.6 \\
1979 & 12.6 & 9.4 & 22.4 & 20.5 & 28.5 & 9.5 & 19.0 \\
1980 & 12.8 & 9.5 & 22.2 & 20.9 & 28.4 & 9.3 & 19.4 \\
1981 & 13.0 & 9.6 & 22.1 & 21.2 & 28.2 & 9.1 & 19.8 \\
1982 & 13.2 & 9.7 & 22.0 & 21.5 & 28.1 & 8.9 & 20.1 \\
1983 & 13.5 & 9.8 & 21.8 & 21.8 & 27.9 & 8.9 & 20.4 \\
1984 & 13.7 & 9.9 & 21.7 & 22.0 & 27.8 & 8.8 & 20.6 \\
1985 & 14.0 & 10.0 & 21.6 & 22.2 & 27.6 & 8.9 & 20.9 \\
1986 & 14.3 & 10.2 & 21.6 & 22.4 & 27.5 & 8.9 & 21.1 \\
1987 & 14.6 & 10.3 & 21.5 & 22.6 & 27.4 & 9.1 & 21.2 \\
1988 & 15.0 & 10.5 & 21.5 & 22.8 & 27.2 & 9.3 & 21.3 \\
1989 & 15.3 & 10.7 & 21.4 & 22.9 & 27.1 & 9.5 & 21.4 \\
1990 & 15.7 & 10.9 & 21.4 & 23.0 & 26.9 & 9.8 & 21.5 \\
1991 & 16.1 & 11.1 & 21.4 & 23.1 & 26.8 & 10.2 & 21.5 \\
1992 & 16.6 & 11.4 & 21.4 & 23.2 & 26.6 & 10.6 & 21.4 \\
1993 & 17.0 & 11.6 & 21.4 & 23.2 & 26.5 & 11.1 & 21.4 \\
1994 & 17.5 & 11.9 & 21.4 & 23.3 & 26.3 & 11.6 & 21.3 \\
1995 & 17.9 & 12.2 & 21.4 & 23.3 & 26.2 & 12.2 & 21.2 \\
1996 & 18.4 & 12.5 & 21.5 & 23.2 & 26.0 & 12.9 & 21.0 \\
1997 & 18.9 & 12.8 & 21.5 & 23.2 & 25.9 & 13.6 & 20.8 \\
1998 & 19.5 & 13.1 & 21.6 & 23.1 & 25.7 & 14.3 & 20.6 \\
1999 & 20.0 & 13.4 & 21.7 & 23.0 & 25.6 & 15.1 & 20.3 \\
2000 & 20.6 & 13.8 & 21.8 & 22.9 & 25.5 & 16.0 & 20.0 \\
\hline & & & & & & &
\end{tabular}

